\title{
Food and Drug Administration commentary on "A new paradigm for obtaining marketing approval for pediatric-sized prosthetic heart valves"
}

\author{
Fernando Aguel, MSE, Steven B. Kurtzman, MD, Sonna Patel-Raman, PhD, \\ Matthew Hillebrenner, MSE, and Bram D. Zuckerman, MD
}

In January 2010, the US Food and Drug Administration (FDA) and AdvaMed organized a workshop for developing a pathway to market for pediatric heart valves. This meeting included representatives from the device industry, medical community, academia, and the FDA. It resulted in a detailed pathway for gaining market approval for pediatric-sized heart valves to address the unmet need for these heart valves.

The article titled, "A new paradigm for obtaining marketing approval for pediatric-sized prosthetic heart valves," by Yoganathan and colleagues, presents this pathway to evaluate the safety and effectiveness of specific types of pediatric heart valves. ${ }^{1}$ In particular, this pathway is presented for smaller sizes of surgically implanted heart valves that already have premarket approval in the United States, comprising the same materials and manufactured by the same processes, and could be reviewed through a premarket approval supplement application.

The underlying theme of this pathway is leveraging our existing knowledge about adult-sized heart valves and encouraging a more global approach for future device development. A key component of this pathway is the total product life cycle approach, with which we can leverage the many facets of the review process to bring these devices to market. With this approach, accelerated wear testing, hydrodynamic testing, flow visualization analysis, and kinematic assessment would be conducted for the new valve sizes. If the new valve size represents worst-case loading conditions, new fatigue testing would also be conducted. Because the new sized valve has the same design and is made of the same materials, however, new animal testing and testing for biocompatibility and sterilization would not need to be conducted. Because there is also presumably extensive clinical experience with the valve model, we can leverage what we know so that only 15 patients per size per position (eg, aortic, mitral) would typically be expected for the clinical trial. A postapproval study would be conducted to assess the long-term safety and effectiveness of the new pediatric-sized valves.

Although the FDA generally defines pediatric subgroups differently (newborn or neonate from birth to 1 month of age; infant older than 1 month to 2 years of age; child older than 2 years to 12 years of age; and adolescent older than 12 years to 21 years of age $)^{2}$ than the classification presented in this article, the age brackets outlined by Yoganathan and colleagues were determined by the clinical subgroup at the FDA-AdvaMed workshop as age groupings with different physiologic conditions. The workshop preclinical team used these conditions to outline the recommended testing conditions for hydrodynamic testing, accelerated wear testing, and loading conditions to be used in any fatigue testing conducted as part of this approach.

The approach presented in the article is consistent with FDA's regulatory practices for surgically implanted heart valves, is capable of providing a reasonable assurance of safety and effectiveness, promotes pediatric device development, and represents the least burdensome approach to the important unmet need of pediatric heart valves.

\section{References}

1. Yoganathan, AP, Fogel M, Gamble S, Morton M, Schmidt P, Secunda J, et al. A new paradigm for obtaining marketing approval for pediatric-sized prosthetic heart valves. J Thorac Cardiovasc Surg. June 21, 2013 [Epub ahead of print].

2. Food and Drug Administration, Center for Devices and Radiological Health, Cen ter for Biologics Evaluation and Research. Guidance for industry and FDA staff, premarket assessment of pediatric medical devices [Internet]. Rockville (MD): US Department of Health and Human Services; May 14, 2004. Available at: http:// www.premierinc.com/safety/topics/pediatrics/downloads/FDA \%20Premarket $\%$ 20Assessment $\% 20$ of \%20Pediatric \%20Medical \%20Devices.pdf. Accessed July 10,2013

\footnotetext{
From the Division of Cardiovascular Devices, Office of Device Evaluation, Center for Devices and Radiological Health, US Food and Drug Administration, Silver Spring, Md.

Disclosures: Authors have nothing to disclose with regard to commercial support.

Received for publication March 31, 2013; revisions received May 23, 2013; accepted for publication June 6, 2013; available ahead of print July 18, 2013.

Address for reprints: Fernando Aguel, MSE, 10903 New Hampshire Ave, WO66

Room 1234, Silver Spring, MD 20993 (E-mail: fernando.aguel@fda.hhs.gov).

J Thorac Cardiovasc Surg 2013;146:887

$0022-5223 / \$ 0.00$

Published by Elsevier Inc. on behalf of The American Association for Thoracic Surgery

http://dx.doi.org/10.1016/j.jtcvs.2013.06.003
} 